Send your letters to the Editor,

British Dental Journal,

64 Wimpole Street

London

W1G 8YS

E-mail bdj@bda.org

Priority will be given to letters less than 500 words long.

Authors must sign the letter, which

may be edited for reasons of space.

\section{TOOTH WHITENING}

Sir, in view of the recent Trading Standards review of over-the-counter (OTC) tooth whitening products, the GDC's declaration that tooth whitening can only be performed legally by a registered dentist and EU report on 'hydrogen peroxide, in its free form and when released, in oral hygiene products and tooth whitening products', it becomes clear that we need to address the situation regarding this procedure.

A recent survey conducted on behalf of the British Academy for Cosmetic Dentistry (BACD) (downloadable from www.bacd.com) revealed that a third of the population is concerned with the look of their teeth. Also, since the smoking ban came into force in England last summer some of our members have reported a $40 \%$ increase in the demand for whitening treatment.

However, Trading Standards discovered that 18 out of 20 tested DIY tooth whitening kits contained illegal levels of hydrogen peroxide. There are even whitening kits from abroad on the internet that contain acids/abrasives that permanently damage teeth.

Their advice to anyone seeking this treatment is to consult a qualified dentist who will provide a comprehensive service and ensure that there are no underlying oral health issues like periodontal disease.

This supports the findings of the EU report which found that products containing over 6\% hydrogen peroxide were unsafe for patients to apply on their own (we expect Trading Standards to crack down on those supplying potentially harmful products). However, products with between $0.1 \%$ and $6 \%$ hydrogen peroxide carry less potential risk only after clinical examination.
This is also important because of the correlation between oral and systemic health. For instance, someone seeking to improve their smile might in fact be inadvertently taking steps towards preventing cardiovascular disease, bacterial pneumonia, diabetes mellitus, etc. OTC products prevent consumers from getting an accurate and complete diagnosis.

It is our belief that all OTC whitening products containing over $0.1 \%$ hydrogen peroxide should be banned outright and that this is enforced to include products offered on the internet. Proper whitening techniques should be taught in dental schools to ensure that every practitioner understands the principles and whitening procedures should be carried out only after examination by a dental professional. Self-administered treatments are dangerous and counterproductive, and whitening toothpastes are ineffective. We should familiarise ourselves with the latest techniques and recommendations, advise our patients of their options and inform them that some of the OTC products cause sensitivity and gum ulceration, and at best do not work at all.

The BACD Board DOI: 10.1038/sj.bdj.2008.356

\section{SEDATION RESTRICTIONS}

Sir, the Society for the Advancement of Anaesthesia in Dentistry (SAAD) notes the comments from the Chairman of the DSTG regarding the provision of conscious sedation for NHS patients ( $B D J$ 2008; 204: 51).

Since the new GDS contract was introduced in 2006 there has been a 'two-tier' system in operation with regard to pain and anxiety control for dental patients in England. This has resulted in many
NHS patients being denied the benefits of sedation for their treatment. PCTs now control which practices control sedation, so it is no longer possible for all GDPs to offer this service. This restriction affects children who need nitrous oxide/oxygen inhalation sedation (relative analgesia), adults who cannot tolerate treatment due to anxiety or phobia and patients who require a prolonged or threatening procedure such as minor oral surgery or multiple crown preparation. Referral to a specialist practice is not the solution as patients will then be treated by a different dentist in whom s/he may have less confidence.

Neither will the introduction of 'Dentists with a Special Interest in Conscious Sedation' (DwSIs) ${ }^{1}$ solve this problem. These sedationists are appointed by PCTs to provide alternative sedation techniques, not the basic techniques which are appropriate for the vast majority of patients and should be available as part of general dental services.

Dentists are not allowed to provide sedation privately as part of an NHS course of treatment. Lifting this restriction would go some way to resolving the problem. Similar restrictions do not, of course, apply to private patients who are able to receive the benefits of anxiety-free dentistry without government interference.

It appears that conscious sedation was overlooked when the new dental contract was introduced. SAAD urges the BDA to investigate this anomaly and negotiate for reform of the contract to enable basic conscious sedation techniques to be practised more widely for the benefit of all patients. Practitioners are encouraged to tackle their PCTs energetically over this matter. 
SAAD would be pleased to receive comments directly from practitioners.

D. Ferry

D. Debuse

SAAD

1. Department of Health/Faculty of General Dental Practice. Guidelines for the appointment of Dentists with a Special Interest in Conscious Sedation. December 2007.

DOI: 10.1038/sj.bdj.2008.357

\section{THE HALL TECHNIQUE}

Sir, as a practising wet fingered paediatric dentist I have considered the 'Hall' technique regarding placement of preformed stainless steel crowns (SSC) and entombing decay on deciduous teeth. My main concern with the 'Hall' procedure is that this technique could precipitate a maxillary or mandibular cellulitis if the decayed tooth undergoes necrosis. It would be difficult to monitor a tooth after a full coverage SSC was placed with radiographs. I have seen severe infection occur post-op when similar compromised paediatric dentistry was performed on a child who had less than stellar cooperation in the dental chair.

Nevertheless, the 'Hall' procedure could possibly serve a need in an area where little or no access to a dentist for the foreseeable future is the state of affairs. For example, in a war zone, or on a mission service in a remote area, I could justify the 'Hall' technique on deciduous teeth. I do not see the need for this procedure in the every day practice of paediatric dentistry.

The administration of infiltration local anaesthesia with mesial, distal, and occlusal preparation of the deciduous tooth for a preformed SSC is a very straightforward affair. Deciduous teeth cut like butter if a coarse diamond is used for the preparation. Removal of decay is very simple. Use of inhalation sedation and topical anaesthesia helps even the most recalcitrant of youngsters allow care to be delivered effectively.

If the decay penetrates the pulp, a pulpotomy is done forthwith. It takes approximately six minutes to perform a stainless steel crown and a pulpotomy for an experienced practitioner. If the practitioner cannot perform the procedure efficiently, the child should be transferred to a practitioner who can.
Children are the most sophisticated of patients. They require finesse and an art of delivery of care that supersedes even the most discriminating of adult patients. Children are not human guinea pigs to be experimented on by the least experienced of the dental team. Rather, it should be the most senior and experienced partner who cares for the child patient. They know what doesn't work!

Thank you for allowing me to express my concerns.

\section{J. P. Murphy \\ Pennsylvania \\ DOI: 10.1038/sj.bdj.2008.358}

\section{SOCIALIST DOGMA}

Sir, dentistry and primary care trusts do not work. All dentists have a creative ability. That is how they are able to do their job. Primary care trusts are a socialist dogma. Primary care trust led dentistry will never work, any more than municipally owned ladies' hairdressing salons would work. It's a simple fact of life.

J. Hartley

Peterborough

DOI: 10.1038/sj.bdj.2008.359

\section{PATIENTS ARE NOT CLIENTS}

Sir, I was appalled to read in the Health for All Wirral PCT Strategy Commissioning Plan 2008-2009 where dentistry is mentioned.

1. The re-design of dental services beyond 2009. Improve service access, improved value for money, reduced cost per head. Nowhere does it mention that patient care should be considerate and of a high standard by dental surgeons who are capable of all facets of dentistry.

2. Nowhere does it give evidence to support the assertion that Wirral PCT overspend is higher than other PCTs countrywide. I would appreciate evidence to support this.

3. How can it be that in a caring profession the most urgent mention is given to containing the increased financial cost? It should be improving patient care.

Dentistry and medicine are not commercial organisations. Patients are not clients or service users. These facts should be foremost in all our minds.
Dentists have a duty of care to their patients which has always overridden other considerations. There is no pretence that this is any longer possible. The NHS dentist is so aware of his or her obligations to their PCT that it is very hard for them to be able to work ethically.

J. Black

Wirral

DOI: $10.1038 /$ sj.bdj.2008.360

\section{ASBESTOS AWARENESS}

Sir, for me, there are few obituaries sadder than the type which featured in the $B D J$ on 22 December 2007 for Mr Richard Bourne.

Here was a story of a self-made and happy family man who dedicated his entire career to helping others when, all of a sudden, it seems, he became ill and was diagnosed with asbestos-induced mesothelioma.

I am a Solicitor and Partner in a Sheffield law firm with a specialist team of lawyers acting on behalf of individuals with occupationally related conditions. In the last 12 months, our work for sufferers of asbestos related cancers has become much more prominent. Being a Sheffield-based practice we have seen our fair share of asbestos related claims for people working in industry and in the last year alone settlements have reached in the region of $€ 1$ million.

The disturbing implication arising from the case of Mr Bourne is that there may be many thousands of people who have worked in the tunnels of University College Hospital London where asbestos was known to be present. That such a risk of exposure has apparently affected so many of the leading medical professionals is a source of great concern. According to a DEFRA report in May 2006 the UK faces between 20,000 and 40,000 new cases of work related cancers every year leading to potential annual costs to the economy of between $£ 29.5$ billion and £59 billion.

The purpose of this unavoidably sombre letter is to raise the awareness of work related cancers, either from asbestos exposures from university life, as at University College, or from more day-today risks such as leaky X-ray machines. In particular if any of your readers have any concerns about their own health 
after reading Mr Bourne's obituary they should be encouraged to take action sooner rather than later. We are happy to lend free initial advice.

C. Fry

chris.fry@wake-smith.com DOI: 10.1038/sj.bdj.2008.361

\section{FORMOCRESOL IN DENTISTRY}

Sir, I am responding to recent articles on the 'safety' of formocresol in dentistry. Having started the debate in 1981, I have had the benefit of reviewing the literature as it has developed, without bias and with consistent regard for scientific principles and protocols. My concern is for your readership, well-meaning clinicians who might be confused by position papers that distort the overwhelming body of evidence that cite the genotoxicity, mutagenicity, carcinogenicity, and toxicity of formaldehyde.

It is ludicrous to suggest that because other medicaments and prescribed medications in dentistry might also have deleterious effects it is therefore 'safe' to use formocresol. It is a 'tad' unscientific to further tell dentists that it is okay to add formaldehyde to their patients' systems since its ingestion/inhalation is a part of life. Repeating the nearly hundred-yearold archaic notion of how to deliver a safe dose by squeezing a soaked cotton pellet is surprising in today's sophisticated techno-based world. Hand-picking studies that have aberrant or inconclusive results when weighed against the accepted evidence becomes self-serving while simultaneously destructive to clinicians seeking the best for their patients.

Much of the research about formaldehyde was firmly established as far back as 30 years ago. Alternative medicaments have been proposed for many years with mixed results. Equal or better clinical outcomes have been demonstrated with some non-aldehyde compounds: ferric sulphate, white mineral trioxide aggregate, white Portland cement and beta-tricalcium phosphate. Systemic distribution after formocresol polpotomy is irrefutable. Formocresol interferes with healing. As recently as March 2008 research has shown that formocresol causes genetic damage.

I urge dentists to rethink their use of formocresol. In 1981 (JADA) and again in 1998 (Journal of Clinical Pediatric Dentistry) I concluded, 'If a medicament like formaldehyde is clearly not a necessary adjunct, then it may be wondered why it is used at all.'

Children should not be exposed to formocresol since there isn't any conclusive evidence warranting its use.

B. B. Lewis

Beverly Hills

DOI: 10.1038/sj.bdj.2008.362

\section{BLEEDING AFTER SCALING}

Sir, our unit recently treated an interesting patient and we would like to share the case with your readers.

A 63-year-old woman presented to the A\&tE Department with a 12 hour history of profuse gingival bleeding. Earlier that day she underwent scaling and polishing of three quadrants performed by a dental hygienist.

Examination showed brisk bleeding from the operative sites. This was slowed with local measures but we were unable to stop it completely. She was admitted to the maxillofacial ward. Bleeding resolved with time and no further treatment was required.

Haematological investigations showed normal haemoglobin and no clotting abnormalities.

The patient was taking antiplatelet medication due to an MI six months previously.

Our department has never heard of a patient requiring admission after a dental scaling and wondered if other units have had similar experiences.

C. McDonald

Dundee

DOI: 10.1038/sj.bdj.2008.363

\section{ACCESS TO SERVICES}

Sir, further to the news story New support programme for sick dentists (BDJ 2008; 204: 227) I would like to clarify for your readers that confidentiality is a fundamental principle in the development of the Practitioner Health Programme to be launched in the autumn this year.

The focus of this programme is on early intervention, to support the health of dentists and doctors so that wherever possible they can continue providing safe and valued practice to their patients. The model developed builds on the extensive experience of Health Support programmes for dentists and doctors in the UK and North America which demonstrate the value of a confidential, dedicated service.

The London prototype programme will provide a great opportunity for dentists who have health problems to access services, where currently they do not do so.

A. Scotland

Director,

National Clinical Assessment Service DOI: 10.1038/sj.bdj.2008.364

\section{WORKER MIGRATION}

Sir, there has been much recent interest in the migration of health workers from developing countries ${ }^{1,2}$ and while the term 'health worker' has been used, most studies have focused on doctors and nurses. ${ }^{3,4}$ Some research has explored career aspirations of dental students from Nigeria, ${ }^{5}$ but information on migration and career patterns of dentists from developing countries is sparse.

We earlier examined country of residence for three classes from a Nigerian medical school and found 40\% living abroad. ${ }^{3}$ As Nigerian dentists follow similar training and career pathways to doctors, we decided to locate members of three graduating classes of the School of Dental Sciences, University of Lagos, Nigeria's oldest and largest dental school, to compare the migration patterns to the doctors'.

We obtained class lists of qualified dentists from 2000, 2002 and 2003, and located class members using formal and informal networks. There were no graduates in 2001 due to university closures. We sent group emails, conducted telephone interviews and used snowballing methods to locate the graduates.

Over the period there were 91 graduates and we located them all. There were 53 females and 38 males. Sixty-eight percent of the cohort lives in Nigeria, while 29 (31.9\%) live abroad. The main receiving countries were the UK and the US.

In this study examining the location of Nigerian dentists after graduation, we found nearly $70 \%$ of the dentists were resident in Nigeria five years after graduation. This contrasts with a similar 


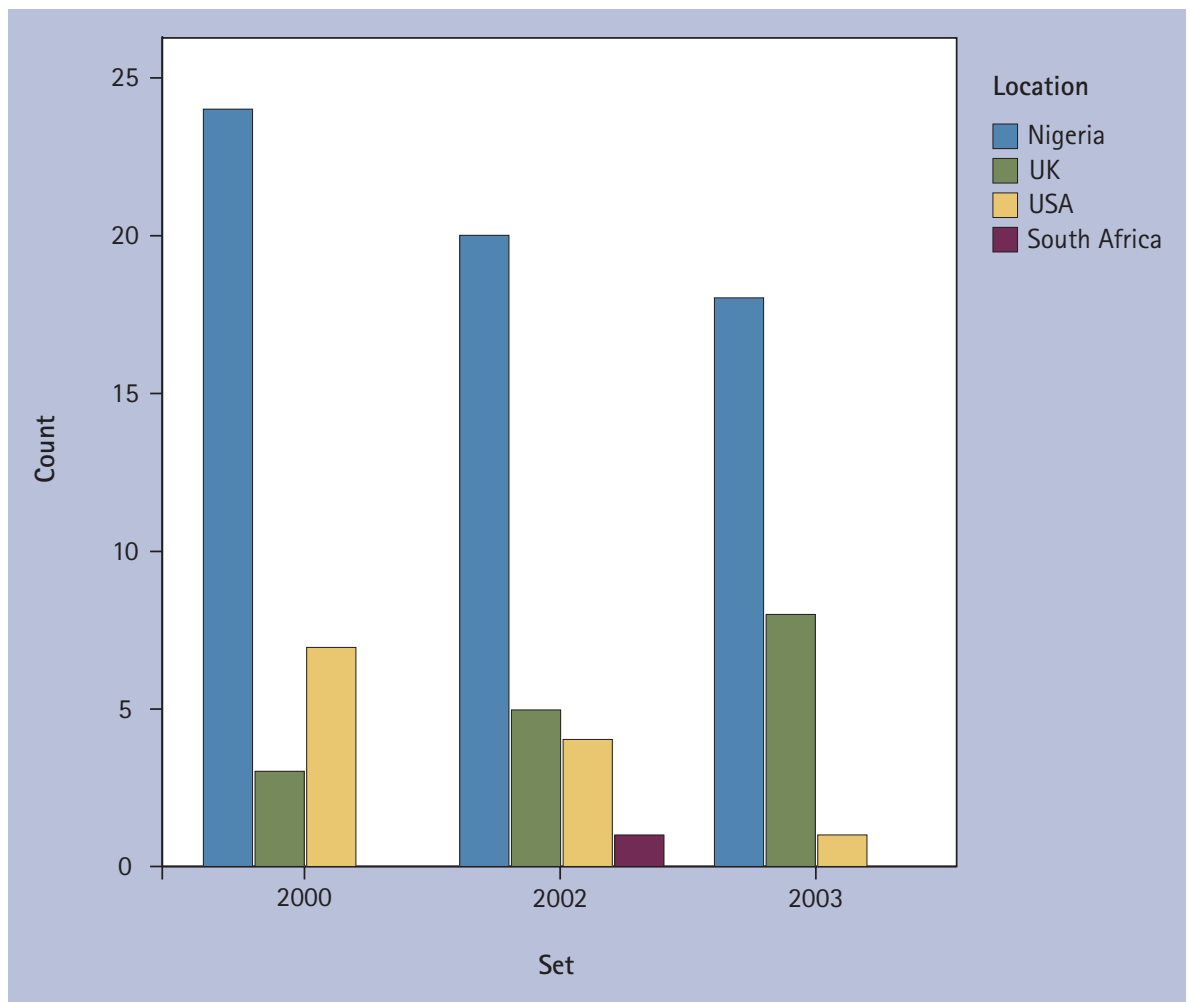

Fig. 1 The number of dental graduates in each country

study of doctors, which found 50\% of medical doctors from recent graduating classes resident in Nigeria. ${ }^{3}$ However, as with doctors, the UK and USA received the majority of migrating dentists (Fig. 1). There were variations within classes with more graduates from the 2003 class resident in the UK and more of the 2000 class resident in the US. Over time, there appears to be an increase in migration, but with fewer migrants to the United States and more migrants to the United Kingdom. This may reflect the US requirement for graduates of foreign dental schools to go through an expensive requalifying programme. We believe that these figures are representative of Nigerian dental schools.

This study suggests differences in the migration patterns of dentists and doctors from Nigeria. Initiatives to address the challenge of human resources for health need to take these into account and explore the underlying reasons to be effective.

B. Azeez, Dundee

I. Anya, Gloucestershire P. Akeredolu, Nigeria O. Albert, London

1. Stilwell B, Diallo K, Zurn P et al. Migration of health-care workers from developing countries: strategic approaches to its management. Bull
World Health Organ 2004; 82: 595-600.

2. World Health Organization. The World Health Report 2006: Working Together for Health. Geneva.

3. Ihekweazu C, Anya I, Anosike E. Nigerian medical graduates: where are they now? Lancet 2005 365: 1847-1848.

4. Dambisya Y M. The fate and career destinations of doctors who qualified at Uganda's Makerere Medical School in 1984: retrospective cohort study. BMJ 2004; 329: 600-601

5. Odusanya 0 O, Nwawolo C C. Career aspiration of house officers in Lagos, Nigeria. Med Educ 2001; 35: 482-487.

DOI: 10.1038/sj.bdj.2008.365

\section{ACCUMULATING CPD HOURS}

Sir, last June the editorial focussed on the journal's CPD scheme (BDJ 2007; 203: 703-704). Whilst I enjoy reading the journal and participate in the CPD quiz, I am surprised that some of the matters raised do not appear to have generated discussion.

Whilst it is clear that the scheme is popular, concern was expressed that for many of the participants it is either their sole or main method of CPD. Although 'the majority of respondents get the majority of questions right most of the time', no mention was made of the simplicity with which such a score can be obtained, or that CPD certification can be gained with a score of zero. I wonder therefore if the popularity of the scheme has more to do with the ease with which
CPD hours can be accumulated rather than any other factor.

When I submitted these comments as feedback (perhaps I am one of the 'detractors' referred to in the editorial), the response was that the GDC does not require a pass mark, and that dentists should be trusted to read the papers thoroughly. Even if we assume that this is so (that's quite an assumption), how does the $B D J$ justify an hour of CPD for a paper that may take only ten minutes or so to read thoroughly?

I am not the first to raise this issue. Dr Storrar did so shortly after the scheme was introduced and the editor at the time responded in a manner similar to your editorial (An easy ride? BDJ 2003; 195: 230). It made me wonder why the GDC does not just require dentists to self-certify their CPD at the end of the year.

The $B D J$ is not alone; other journals offer similar schemes. Verifiable CPD can be obtained in all manner of ways including wandering around a tradeshow, logging into and browsing a website, or answering a few questions about a manufacturer's products. Its value has been diminished, with commercial concerns taking precedence over educational.

Practitioners who are committed to best practice will always keep their skills up to date without the stick of a mandatory CPD scheme. However, it serves an important purpose by allowing us to reflect on our development and demonstrate commitment to excellence in patient care. That activity should therefore have credibility, which infers setting and enforcing quality control standards to which providers of CPD (myself included) should adhere. The General Dental Council needs to address this matter, and I hope that others who are involved in the provision of meaningful postgraduate education share my concerns.

A. Gould London

DOI: $10.1038 /$ sj.bdj.2008.366

\section{TRAINEE FINANCES}

Sir, I am writing regarding the financial difficulties faced by trainees in oral medicine and oral and maxillofacial 
surgery when reading for their second degree, be that in medicine or dentistry.

Recently there has been a lack of suitable candidates for registrar training posts in both specialities but particularly in my chosen career pathway of oral medicine. One of the main deterrents for prospective candidates is the lack of financial support provided by the NHS during their period of study towards a second degree. A greatly reduced regular income, course fees running into thousands of pounds (tens of thousands for non EU graduates), loss of superannuation payments and an unfair NHS Bursary system all add to the reasons why not to specialise in these disciplines.

I am currently part of the 4th year cohort of the MBChB course at the University of Birmingham Medical School and recently enquired with the NHS Student Bursary Service about receiving an NHS Bursary in my 4th year. Although all medical students can claim a bursary in their final year, only students undertaking a four year 'graduate entry course' are entitled to an additional bursary in their penultimate year. According to the Bursary Service dentists are not considered graduate entry students, hence are not entitled to the assistance. This is despite the fact that generally, dental graduates will be older and more likely to have additional financial responsibilities such as mortgages and children when compared to non dental graduate students.

Another negative aspect of reading towards the second degree is the loss of superannuation payments during the period of study; and the resultant detrimental effect on your NHS pension. I have been told by the NHS Business Services Authority that not surprisingly the NHS pension is inflexible in this respect. Moreover, as of 31 March 2008 , the ability to purchase extra years will be replaced with a new 'additional purchase facility' which allows a top up of superannuation payments to provide a maximum of $£ 5,000$ pa in extra payment on retirement. I will leave discussion about which is the better deal to the accountants and the financially astute. However, one question remains unanswered, that is will I be forced to work longer than my general practice colleagues in order to attain a full pension?

The British Society of Oral Medicine, although sympathetic and supportive of the cause of prospective registrars, was unable to provide any further assistance. The British Association of Oral and Maxillofacial Surgeons were also sympathetic but suggested that they are working with the Postgraduate Medical Education and Training Board to try and establish the principle that commencement of the second degree in oral and maxillofacial surgery should mark the starting point of specialist training, and as such it should be funded. Any decisions here could cross over to additionally affect oral medicine training. It remains to be seen if any substantial progress will be made towards improving the situation.

\section{R. McMillan Birmingham \\ DOI: 10.1038/sj.bdj.2008.367}

\section{SMELL THE COFFEE}

Sir, logic, from its Greek origin, is defined as the art and science of reasoning; a chain of reasoning, a correct or incorrect use of argument.

Govern, from its Latin root, is defined variously as to rule with authority over a state or people or to sway, direct, influence or be in command of a state or people.

It would be fair to assume that a government acts on a logical basis because if its logicality was in doubt the chances of re-election would be slim, discounting all other factors. It may well be that the logic is disguised from outward view and a more acceptable face needs to be displayed to the public being governed. This is the task of the 'spin doctors'; to make the unpalatable acceptable.

Having made this leap of faith, ie that government is based on reasoning, which is scarcely borne out by history, it has to be assumed that the training programmes which are under way in dentistry are conceived to a plan. What can that plan be?

Let us look at what educational programmes are going forward.
There are expanded training programmes for therapists whose duties are slowly widening. There are plans to broaden the activities of dental nurses enabling them legally to perform more dental tasks and there are larger intakes in most dental schools and two new schools starting up. In a few years; in 2010, home trained graduates and overseas graduates will combine to enlarge the dental workforce so that there will be more qualified dentists in Britain than ever before, and more therapists than ever before. In England and Wales the government's stated aim is to 'simplify' the treatment provided under the NHS which will tend to provide more work for therapists and will leave the dentists with less and less to do.

Will we reach the stage where the NHS employs therapists to do the 'simpler' courses of treatment which will be the lion's share of that provided and a few dentists to supervise the triage process? Most 'complex' treatment will be carried out by those with added skills who will work largely in the private sector with an absolute minimum within the NHS to deal with the unexpectedly complex case.

Add to this the limitations of a finite budget which will restrict the number of contracts available and logic dictates that there will be considerable unemployment of dentists. Reason also tells us that there will be immense pressure on private fees as competition for survival will create a market almost akin to the supermarket economy. But how will patients judge quality? That is a vexed question which is hard to answer at this time.

Is this the grand master plan?

Well, if government is a logic-based process the only conclusion one can draw is that this is the plan to subdue the profession. Control, it seems, is the order of the day.

The profession needs to smell the coffee and make plans accordingly.

L. Ellman By email DOI: 10.1038/sj.bdj.2008.368 